\title{
Competências e habilidades do Movimento Escoteiro, no ramo lobinho, retratados nas árvores de conhecimento de Pierre Lévy e Michel Authier
}

Competences and skills of scout movement, in the little wolf division, represented in the knowledge trees of Pierre Lévy and Michel Authier

Recebimento: 11/12/2020 - Aceite: 1501/2021 - Publicação: 01/02/2021

Processo de Avaliação: Double Blind Review

Paula Del Priori ${ }^{1}$

Mestranda em Administração pela Pontifícia Univeridade Católica de São Paulo (PUC$\mathrm{SP})$

priorepd@gmail.com

https://orcid.org/0000-0003-2155-4312

Sandra Joyce Silva de Souza

Mestranda em Administração pela Pontifícia Univeridade Católica de São Paulo (PUC$\mathrm{SP})$

sandrajoycesouza@gmail.com

https://orcid.org/0000-0001-8686-9572

Valmir de Santana Santos Júnior

Mestrando em Administração pela Pontifícia Univeridade Católica de São Paulo (PUC$\mathrm{SP})$

valmirss@hotmail.com

\section{RESUMO}

Concebido pela palavra competência, os conhecimentos, as habilidades e as atitudes quando internalizados e colocados em ação, agregam valor ao indivíduo e à comunidade em que está inserido. Estas competências podem ser retratadas visualmente, segundo a

\footnotetext{
${ }^{1}$ Autor para correspondência: Pontifícia Universidade Católica de São Paulo (PUC-SP): Rua Monte Alegre, 954- São Paulo- SP, CEP 05014-901, Brasil
} 
proposta de Lévy e Authier (1995), por um conceito de árvores de conhecimento que captura, reconhece, avalia e organiza os saberes dos indivíduos de uma determinada comunidade de maneira tecnológica e em tempo real. O presente artigo propõe conexão entre o conceito de árvores de conhecimento com a comunidade do Movimento Escoteiro, mais especificamente os jovens do ramo lobinho. O escotismo é um movimento educacional que tem por objetivo contribuir para o desenvolvimento próspero e saudável dos jovens de sua comunidade tendo a natureza como fio condutor de seu universo. Através de um método educativo próprio, disponibiliza inúmeras atividades comuns e organizadas de acordo com a faixa etária, denominada ramos, oportunizando a aquisição de competências de desenvolvimento integral de educação para a vida em complemento à família, escola e outras instituições.

Palavras-chave: competências, saberes, movimento escoteiro, árvores de conhecimento

\section{ABSTRACT}

Conceived by the word competence, knowledge, skills and atitudes when internalizes and put into action, add value to the individual and the community in which it is inserted. These skills can be portrayed visually according to the proposal of Lévy and Authier (1995), by a concept of knowledge trees that captures, recognizes, evaluates and organizes the individual knowledges in a given community in a tecnological way and in real time. This article proposes a connection between the concept of knowledge trees and the Scout Movement communnity, more specifically young people in the cub scounting. Scounting is an educational movement that aims to contribute to the prosperous and healthy development of young people in your community with nature as the guide. Throught its own educational method, it offers numerous commom activities organizes according to the age group, providing the opportunity to acquire skills for the integral development of education for life in addition to family, school and other institutions.

Keywords: skills, knowledge, scout movement, knowledge trees 


\section{INTRODUÇÃ̃O}

O presente artigo orientado pela perspectiva de reflexão e discussão de um ensaio teórico sobre como identificar os saberes praticados dentro do movimento escoteiro, para os meninos e meninas, na faixa etária de seis e meio a onze anos incompletos, que correspondem ao Ramo Lobinho, por meio do conceito das árvores de conhecimento de Lévy e Authier (1995). Este conceito organiza os conhecimentos, habilidades e atitudes resumidos como saberes de uma mesma comunidade em uma representação gráfica de árvore composta por caule, galhos e folhas. O objetivo deste trabalho é compreender as sinergias entre a organização dos saberes do movimento escoteiro e sua disposição segundo a estrutura das árvores de conhecimento, levando à seguinte pergunta de pesquisa: "Existe a oportunidade de identificar e organizar os saberes do movimento escoteiro, Ramo Lobinho, segundo o conceito de árvores de conhecimento de Lévy e Authier (1995)?”

\section{REFERENCIAL TEÓRICO}

\subsection{Competências, Habilidades e Atitudes}

O conceito de competência é amplamente estudado e teve sua origem marcada pelos estudos de McClelland (1973) que partiu da análise dos testes de inteligência tradicional e testes de aptidão. Segundo McClelland (1973) a pontuação alta no teste de inteligência e as notas na escola não preveem a competência real em muitos resultados da vida, consegue ter apenas um viés do nível social do indivíduo. McClelland (1973) defende que o teste de competência deve ser feito através da amostragem por critério, ou seja, se o teste é sobre saber dirigir um carro, deve ser entregue o carro à pessoa que quer comprovar sua competência, que corresponde ao critério e não lápis e papel. O que deve ser estudado é a análise comportamental. Outro critério defendido é que os testes devem ser projetados para refletir as mudanças no que o indivíduo aprendeu, ou seja o progresso educacional do indivíduo. Testes devem avaliar as competências sociais, de liderança, habilidades interpessoais etc.

Segundo McClelland (1973), os testes devem conter não apenas competências cognitivas tradicionais tais como ler, escrever, calcular, mas também o que ele denomina variáveis de personalidade. São variáveis de personalidade para McClelland habilidade de 
comunicação, paciência, estabelecimento de metas realistas, desenvolvimento do ego no sentido de tomar iniciativa.

Corroborando com os pensamentos de McClelland (1973), com cerne nas competências do indivíduo, porém com viés do mercado de trabalho, Mirabile (1997) evoluiu o conceito de competência definindo como conhecimentos, habilidades e aptidões ou outras características para desempenhar uma função de alta performance. Por conhecimentos, Mirabile (1997) entende como o conjunto de informações para desempenhar uma função, habilidade como um talento que pode ser nato ou não, porém o indivíduo tem uma predisposição natural em desenvolver.

Fleury e Fleury (2001) definem competência como "uma palavra do senso comum, utilizada para designar uma pessoa qualificada para realizar alguma coisa." Ou ainda "um estoque de recursos, que o indivíduo detém.” Os autores Fleury e Fleury (2001) definem competência como "um saber agir responsável e reconhecido, que implica mobilizar, integrar, transferir conhecimentos, recursos e habilidades, que agreguem valor econômico à organização e valor social ao indivíduo", conforme apresenta a figura 1:

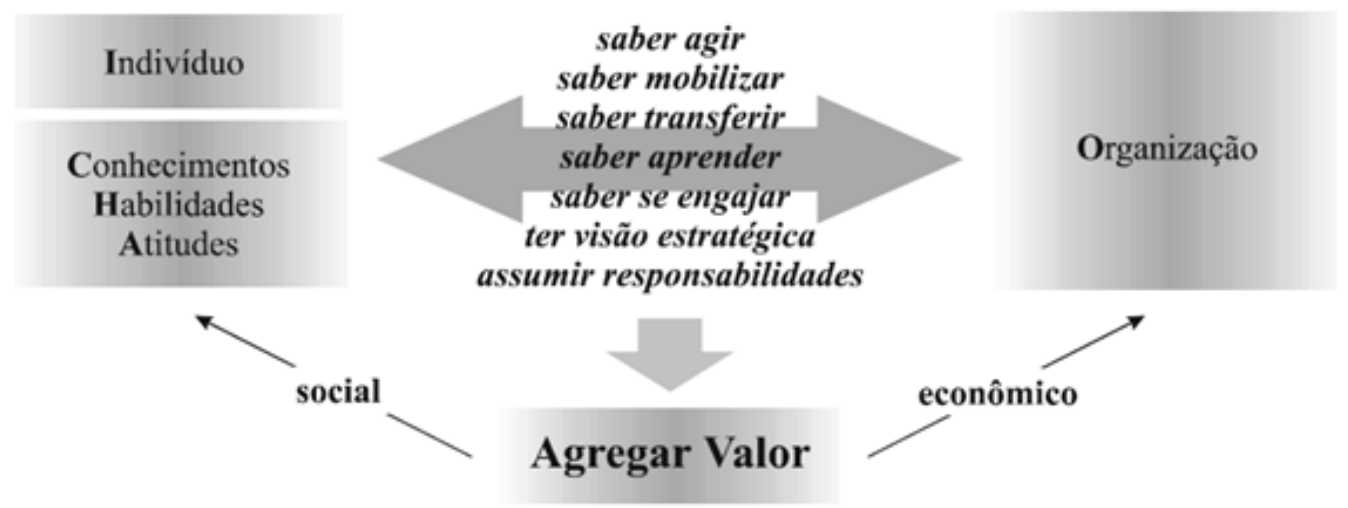

Figura 1 - Competências como Fonte de Valor para o indivíduo e para a Organização.

Fonte: Fleury e Fleury (2001, p. 188).

Saber agir é saber o que e por que faz, inclui-se também saber julgar, escolher e decidir. Saber mobilizar está relacionado a criar sinergias e mobilizar recursos e 
competências. Saber transferir refere-se à comunicação no sentido de transmitir informações e conhecimentos. Saber aprender concerne a trabalhar conhecimentos e saber desenvolver-se. Saber se engajar comprometendo-se e ter visão estratégica está conectado ao viés empresarial de Fleury e Fleury (2001) que se preocupa com o desempenho social do indivíduo e econômico da organização.

Para Fleury e Fleury (2001) o conceito de competência é pensado como conjunto de conhecimentos, habilidades e atitudes (isto é, conjunto de capacidades humanas) que justificam um alto desempenho, acreditando-se que os melhores desempenhos estão fundamentados na inteligência e personalidade das pessoas.

Para Perrenoud (1999) as competências têm diversos significados, sua definição é "uma capacidade de agir eficazmente em um determinado tipo de situação, apoiada em conhecimentos, mas sem limitar-se a eles. Para enfrentar uma situação da melhor maneira possível, deve-se, via de regra, pôr em ação e em sinergia vários recursos cognitivos complementares, entre os quais estão os conhecimentos." Perrenoud (1999) considera que a competência não é a implementação racional pura e simples de conhecimentos, mas é a mobilização dos conhecimentos científicos no momento certo para resolver uma situação concreta. $\mathrm{O}$ autor compara um jogo de xadrez entre um campeão e um computador, explicando que o computador armazena vários jogos e jogadas e vence na grande maioria das vezes, porém em uma situação inédita apenas o humano pode se beneficiar de esquemas cognitivos aplicados a decisões não racionais, chamado de heurísticos.

Perrenoud (1999, p. 7) “a construção de competências, pois, é inseparável da formação de esquemas de mobilização dos conhecimentos com discernimento, em tempo real, ao serviço de uma ação eficaz." O esquema de mobilização dos conhecimentos de recursos cognitivos vai sendo desenvolvido e consolidado através da prática. Conhecimento e competências são complementares segundo Perrenout (1999).

Durand (1998) balizou o conceito de competência nos estudos em Educação de Pestallozi (1972) que se referia às chaves de aprendizado como cabeça, mão e coração. O paralelo de Durand (1998) encontra-se nas três dimensões -knowledge, know-how and attitudes - traduzido por conhecimentos, habilidades e atitudes intitulado CHA. Por conhecimentos Durand (1998) entende por um conjunto de informações estruturadas com a capacidade de transformar os dados em informações aceitáveis para serem utilizadas, são os saberes. Habilidade refere-se à capacidade de agir de forma concreta de acordo com 
objetivos predefinidos, não exclui o conhecimento e, também não necessita um entendimento completo da correta operação das capacidades e habilidades, sendo, portanto, uma dimensão empírica, é o saber fazer. Atitudes são caracterizadas por ações e comportamentos movidos pela determinação em alcançar algo, simplificado como querer fazer. Em consonância com Perrenoud (1999) para Durand (1998), as três dimensões são interdependentes e complementares.

Para transformar conhecimentos, habilidades e atitudes anteriores, segundo Brandão (2009) o indivíduo deve aprender e uma vez que o conteúdo é assimilado, este modifica conhecimentos, habilidades e atitudes modificando também a competência do mesmo que sempre está sendo construída e aperfeiçoada. Com esta construção progressiva de conhecimentos, habilidades e atitudes as comunidades podem se organizar conforme as competências no sentido de mapeá-las, visualizando a posição de saberes em comparação a outras pessoas e entender quais direções estão indo. Este conceito de mensurar os saberes de uma comunidade em um mesmo local ou com os mesmos objetivos e conseguir visualizar, foi desenvolvido por Lévy e Authier (1995) e denomina-se árvore de conhecimento.

\section{2. Árvores de Conhecimento}

Lévy e Authier (1995, p.101) "de todos os saberes da vida, somente uma ínfima parte é acompanhada por um reconhecimento oficial de títulos ou diplomas. Mas uma infinidade de conhecimentos, que todos podem possuir em um momento ou em outro, aqui e ali, sua pertinência econômica, lúdica, social, científica etc circulam clandestinamente, crescem em silêncio, invisíveis, atuantes, prontas para servir."

Lévy e Authier (1995) defendem a extensão das ações educativas para além dos títulos e diplomas, ampliando o horizonte afirmando que "todo saber pode ter uma utilidade econômica ou social" Lévy e Authier (1995, p.43), o que tradicionalmente não é reconhecido pela pedagogia oficial.

O sistema da árvore de conhecimento segundo Lévy e Authier (1995) é a sistematização e a reunião das competências de um coletivo garantindo visibilidade e captura destes saberes no formato de uma árvore. A árvore de conhecimento é composta 
por de três tipos de imagens, quatro bancos de informações e uma moeda de troca e avaliação.

Os três tipos de imagens correspondem a menor escala às patentes, que representam os saberes elementares dos indivíduos, um conjunto de patentes de um mesmo indivíduo são simbolizados pelos brasões, que por sua vez estão nos galhos da árvore que compõe a terceira imagem. Um conjunto de patentes ou de especialidades formam o indivíduo que na árvore de conhecimento é representada pelo brasão. O reconhecimento do saber elementar na árvore do conhecimento de Lévy e Authier (1995) vem por meio de uma prova que é elaborada e avaliada pelos especialistas, o indivíduo que é aprovado recebe um diploma e merece obter a patente que consequentemente enriquece o brasão.

Quatro bancos de informação referem-se as patentes, formações, competências (brasões) e perfis. O banco das patentes contém a descrição do saber que ela simboliza e a prova para obtê-la. A prova pode ser um exercício de simulação, uma memória, de um testemunho de pessoas competentes etc. O banco das formações, são as informações práticas para a preparação para obtenção da patente. $\mathrm{O}$ banco dos brasões ou armorial é o conjunto dos brasões dos membros da comunidade de saber que estão organizados nas árvores de conhecimento. $\mathrm{O}$ armorial pode ser entendido como a caixa de correspondência individual e confidencial de cada proprietário de brasão e tem sua utilidade quando os empregadores buscam certas competências e endereçam uma mensagem ao proprietário daquele brasão. O banco de perfis orienta a evolução dos brasões pois é iniciado por empregadores que depositam brasões ideais ou perfis, indicando a necessidade de algum tipo de competência necessária para empregar. Temos assim a bolsa do saber que, de um lado, encontra-se a oferta por competências, representada pelo armorial e, do outro lado, a demanda por competências representada pelo banco de perfis. Visualizando assim em uma árvore de saber a ligação entre oferta e demanda que é representado pela proximidade das imagens.

A moeda de troca e avaliação é representada segundo Lévy e Authier (1995) pelo Sol (Standard Open Learning unit) traduzido por unidade aberta de aprendizagem padrão que é inconversível em moeda clássica e com conceito diferente do mercantil pois quem transmite não a perde. O Sol valoriza as patentes que por sua vez tem seu valor impactado por vários critérios tais como conjunto dos comportamentos da comunidade do saber, do que é mais procurado naquela comunidade, na prova para obtenção da patente. 
Toda esta estrutura de árvore de conhecimento, como um mapa vivo e fiel do espaço do saber, pode ser calculada através do software criado por Lévy e Authier (1995) como um mecanismo tecnológico em tempo real de captura, reconhecimento, avaliação e organização das competências partindo dos saberes de cada indivíduo de uma mesma comunidade onde a evolução de qualquer elemento transforma a árvore que está contido.

Este conceito de árvore de conhecimento de Lévy e Authier (1995) pode haver uma coesão com o movimento escoteiro onde entendendo o movimento escoteiro como uma comunidade, tem seu coletivo um conjunto de indivíduos que colabora para o crescimento de uma mesma árvore através de suas competências.

\subsection{Movimento Escoteiro}

Fundado por um condecorado militar de guerra, Robert Stephenson Smyth BadenPowell, na Inglaterra em 1907 o movimento escoteiro é mundial, educacional, voluntário, apartidário e sem fins lucrativos. O início ocorreu no dia 1 de agosto de 1907 quando Baden-Powell percebeu a necessidade de testificar algumas de suas ideias e desenvolver seu programa para os jovens. Com isso, no dia 9 de agosto daquele ano, levou 24 rapazes para um acampamento na ilha de Brownsea no Canal da Mancha, que ficaria estabelecido como o primeiro acampamento escoteiro da História, Nagy (1987).

Em 2019, conforme dados da Organização Mundial do Movimento Escoteiro (World Organization of the Scout Movement - WOSM), o escotismo movimenta mais de 54 milhões de pessoas em 171 organizações membros no mundo.

Compreende-se que o objetivo inicial de Baden-Powell, em contribuir com os jovens para um desenvolvimento próspero e saudável, permanece como o principal objetivo do escotismo em todo o mundo. Segundo Nagy (1987), a natureza era o conceitochave que, como um fio condutor, se expandia por toda a filosofia escoteira, em um universo no qual as aspirações e os sonhos dos adolescentes podiam ser realizados por eles mesmos. 


\subsection{Movimento Escoteiro no Brasil}

Em 1910 o escotismo foi inserido no Brasil, através de um grupo de oficiais da Marinha Brasileira, vindo da Europa, que trouxeram consigo uniformes, acessórios escoteiros e, de acordo com Thomé (2006, p.176) "o interesse de semear o movimento no Brasil", após perceber o grande sucesso que o Movimento Escoteiro fazia na Inglaterra. Rapidamente o grupo se programou para criar a primeira associação escoteira, chamada de Centro de Boys Scouts do Brasil, no Rio de Janeiro.

Conforme o estatuto da União dos Escoteiros do Brasil-UEB (2011, p.8):

Art. $5^{\circ}$.: o Escotismo é um movimento educacional de jovens, sem vínculo a partidos políticos, voluntário, que conta com a colaboração de adultos, e valoriza a participação de pessoas de todas as origens sociais, raças e crenças, de acordo com seu Propósito, seus Princípios e o Método Escoteiro concebidos pelo Fundador Baden-Powell e adotados pela UEB.

A UEB é a única associação reconhecida, filiada e autorizada, pela Organização Mundial do Movimento Escoteiro (World Organization of the Scout Movement - WOSM), a praticar o Escotismo no Brasil, uma organização do terceiro setor sem fins lucrativos que atende crianças, adolescentes e jovens por meio de um programa educativo próprio, UEB (2018). Ferramenta de educação não formal, o Escotismo ultrapassa as barreiras e se firma como um movimento educacional por proporcionar aos jovens desenvolvimento em diferentes áreas, de forma sempre contemporânea e variada, Thomé (2006).

Educação não formal segundo Smith (1996) é qualquer atividade organizada fora do sistema formal de educação que se destina a servir uma determinada classe de pessoa que buscam certos tipos de educação com objetivos educacionais definidos. De acordo com o documento da Unesco (2011) educação não formal representa a educação que é institucionalizada, intencional e articulada por um provedor de educação. E a “característica definidora da educação não formal é que ela é uma adição, alternativa e/ou complemento da educação formal no processo de aprendizagem ao longo da vida dos indivíduos.” Unesco (2011, p.11).

Conforme informações da UEB (2018), nacionalmente o órgão é administrado em três níveis. Nacional: com autoridade em todo o território brasileiro, é dirigido pela Diretoria Executiva Nacional, que comanda a equipe de profissionais do Escritório Nacional, com sede em Curitiba (PR); Regional: denominado Região Escoteira, abrange 
um estado da federação, e atua como uma filial de nível nacional, sendo formado por Diretorias eleitas localmente e Local: constituído pelos grupos escoteiros e seções escoteiras autônomas, locais onde acontece a prática do Escotismo e o contato direto com os jovens.

Para melhor planejamento das atividades, o Movimento Escoteiro é dividido em quatro ramos, conforme a faixa etária dos jovens. como demonstrado na Tabela 1 a seguir:

Tabela 1. Distribuição do Movimento Escoteiro em ramos (UEB, 2019)

\begin{tabular}{c|c|c}
\hline Ramo & Faixa etária & Enfase educativa \\
\hline Lobinho & 6,5 a 10 anos & Processo de socialização da criança \\
\hline Escoteiro & 11 a 14 anos & Processo de criação e ampliação da autonomia \\
\hline Pênior & 15 a 17 anos & $\begin{array}{c}\text { Processo de autoconhecimento, aceitação e aprimoramento } \\
\text { das características pessoais, auxiliando o jovem na } \\
\text { formação de sua identidade e a superar os principais } \\
\text { desafios com que se depara nessa etapa da vida. }\end{array}$ \\
\hline Pioneiro & 18 a 21 anos & $\begin{array}{c}\text { Processo de integração do jovem à sociedade, } \\
\text { privilegiando a expressão da cidadania, auxiliando o } \\
\text { jovem a colocar em prática os valores da Promessa e da } \\
\text { Lei Escoteiras no mundo mais amplo em que passa a viver. }\end{array}$ \\
\hline
\end{tabular}

Fonte: Elaborado pelos autores

A participação de jovens e adultos no escotismo acontece de forma voluntária, conforme definido, sem vinculação a uma orientação político-partidária e aberta para pessoas de quaisquer raças, credos e origens. O parágrafo inicial do artigo mencionado apresenta a definição do propósito do Movimento Escoteiro (2011, p .8):

“ $\S 1^{\circ}$ - O Propósito do Movimento Escoteiro é contribuir para que os jovens assumam seu próprio desenvolvimento, especialmente do caráter, ajudando-os a realizar suas plenas potencialidades físicas, intelectuais, sociais, afetivas e espirituais, como cidadãos responsáveis, participante e úteis em suas comunidades, conforme definido pelo seu projeto educativo."

\subsection{Método Escoteiro}

O escotismo acontece através da interação dos jovens com o escotista, terminologia usada no Brasil para designar os educadores que atuam no Movimento Escoteiro. O diferencial do escotismo, é o chamado Método Escoteiro, que é o projeto educativo do movimento, conforme nos indica Santos \& Feldens (2014, p.19) “permeando toda a vida, 
todas as capacidades que nos compõem, conhecidas ou não". Ele é pautado por fundamentos definido por seu fundador, Baden-Powell, de desenvolvimento integral e educação para vida complementando o esforço da família, da escola e de outras instituições. Tendo a missão de educação para as pessoas que contribuirão para a transformação para o mundo por meio de um sistema de autoeducação progressivo. Segundo a UEB (2019), o projeto educativo é composto por cinco elementos.

O primeiro dos elementos é a aceitação da promessa e da lei escoteira, onde o membro da UEB aceita os valores apresentados nos textos da lei e da promessa; o segundo elemento é o de aprender fazendo; o elemento seguinte aborda o tópico vida em equipe, as atividades são realizadas em equipes, durante a vivência dos jovens no escotismo, que tem por objetivo promover a aceitação progressiva das responsabilidades, a disciplina quanto aos afazeres assumidos voluntariamente e as capacidades de cooperação e liderança; o quarto elemento refere-se às atividades progressivas, atraentes e variadas, incentivadas pelo sistema de distintivos, estas atividades dentro do Movimento Escoteiro, podem assumir várias formas, seja através de jogos que podem ser direcionados a uma série de objetivos diferentes, dentre os quais a interação com a comunidade e a vivência ao ar livre são partes componentes; o quinto e último elemento refere-se ao desenvolvimento pessoal com orientação individual, de modo que cada jovem deve ser visto por seu educador com individualidade, interesses e necessidades particulares.

O ponto de partida do método educativo é a adesão à promessa e à Lei Escoteira que é um instrumento educativo que contém os princípios que guiam o movimento escoteiro portanto devem ser comuns a todos os membros do movimento. De acordo com a UEB (2019, p.13) a "Lei Escoteira, é composta por dez artigos:

I. O escoteiro é honrado e digno de confiança;

II. O escoteiro é leal;

III. O escoteiro está sempre alerta para ajudar o próximo e pratica diariamente uma boa ação;

IV. O escoteiro é amigo de todos e irmão dos demais escoteiros;

V. O escoteiro é cortês;

VI. O escoteiro é bom para os animais e as plantas;

VII. O escoteiro é obediente e disciplinado;

VIII. O escoteiro é alegre e sorri nas dificuldades;

IX. O escoteiro é econômico e respeita o bem alheio;

$\mathrm{X}$. O escoteiro é limpo de corpo e alma. 
A aceitação da promessa firma o compromisso do escoteiro com o movimento sendo que cada ramo do movimento escoteiro possui uma promessa específica. O foco do nosso trabalho é o Ramo Lobinho, assim conforme a UEB (2019, p.12) a promessa do Ramo Lobinho é: "Prometo fazer o melhor possível para: cumprir meus deveres para com Deus e minha Pátria; obedecer à Lei do Lobinho e fazer todos os dias uma boa ação.”

A aprendizagem no método educativo escoteiro se desenvolve pelo serviço, pela ação e pelo jogo. A aprendizagem pelo serviço é realizada através da atitude solidária com ações pertinentes que ajudam a comunidade para que o jovem se desenvolva em várias dimensões aprendendo a se respeitar e respeitar os demais contribuindo para a comunidade. A aprendizagem pela ação é reflexo da educação ativa sugerida pelo movimento com autodesenvolvimento por meio de observação, descobrimento, elaboração, inovação, experimentação, desenvolvendo e consolidando conhecimentos, habilidades e atitudes. A aprendizagem através de jogos é uma "oportunidade para experimentar, aventurar, imaginar, sonhar, projetar, construir, criar e recriar a realidade" (Projeto Educativo, 2 Edição 2017- p.23) sendo uma aprendizagem significativa onde o jovem é protagonista dos diferentes papéis que terá no jogo.

Ausubel (1968) conceituou aprendizagem significativa com um processo de aquisição de novos significados em que uma informação nova se relaciona a estrutura do conhecimento absorvida e armazenada pelo indivíduo no passado, montando mais e mais conhecimento como um espiral. A todo momento o indivíduo está em processo de aprendizagem que de acordo com Ausubel (1968) é um processo de armazenamento de informações no cérebro construindo uma estrutura que se organiza em áreas do conhecimento. Esse armazenamento de informações vai sendo composto e aumentado conforme as experiências e aprendizados individuais, formando uma predisposição para aprender.

A organização das oportunidades de aprendizagem no movimento escoteiro, ocorrem como um processo progressivo de autoeducação, que conforme Thomé (2006) são concretizadas através da realização de atividades que geram experiências educativas, oportunizam a aquisição de competências e impulsionam o aprimoramento da personalidade, tanto no campo individual, quanto no campo coletivo. 
O propósito do projeto educativo do movimento escoteiro "é contribuir para que os jovens assumam seu próprio desenvolvimento, especialmente do caráter, ajudando-os a realizar suas plenas potencialidades físicas, intelectuais, sociais, afetivas e espirituais, como cidadãos responsáveis, participantes e úteis em suas comunidades." (Projeto Educativo, 2 Edição 2017- p.7).

Inicialmente Baden Powell não havia estipulado um limite de idade mínima, nem máxima para o ingresso de jovens no Movimento Escoteiro. Em decorrência disso, as tropas tinham jovens cujas idades variavam entre 9 a 18 anos. Assim, Thomé (2006, p.179) "a primeira tropa desestruturou-se, os mais velhos não desejavam misturar-se com os pequenos e estes não conseguiram acompanhar as vigorosas atividades feitas pelos escoteiros".

\subsection{Ramo Lobinho}

Conforme UEB (1998) o Ramo Lobinho é composto por meninos e meninas na faixa etária de 6,5 a 11 anos incompletos. São chamados, respectivamente, de lobinhos e lobinhas, que representam os filhotes de lobos. O grupo integrado por todos, recebe o nome de Alcatéia: uma sociedade de crianças que, assim como lobos, decidiu viver diante de uma mesma lei onde cada um é importante. As Alcateias são formadas por duas a quatro matilhas que, por sua parte, possuem de quatro a seis crianças. Dentro de cada uma dessas matilhas, duas crianças são eleitas para desempenhar o papel de liderança, a orientação dos manuais é de que para cada matilha, exista um escotista responsável, o lema do ramo é "Sempre Alerta".

A parte lúdica oferecida às crianças deste ramo está correlacionada à obra de Rudyar Kipling O Livro da Jângal, resumido em Mowgli, O Menino-Lobo, entre um dos best sellers do início do século XX, que Baden-Powell escolheu e utilizou, com a autorização do autor, para dar vida ao Ramo Lobinho, e que se conserva atual, mesmo nos dias de hoje, Nagy (1987).

As crianças do Ramo Lobinho não acreditam que são animais, nem se portam como tal, entretanto brincam de sê-lo como integrantes de um grupo que possuem determinadas características de organização e que distingue com seus próprios sinais e símbolos. Corroborando com a importância das atividades recreativas, o Referencial Curricular 
Nacional para a Educação Infantil (1998, p.27), apresenta a brincadeira como uma linguagem:

\footnotetext{
"A brincadeira é uma linguagem infantil que mantém um vínculo essencial com aquilo que é o "não-brincar". Se a brincadeira é uma ação que ocorre no plano da imaginação isto implica que aquele que brinca tenha o domínio da linguagem simbólica. Isto quer dizer que é preciso haver consciência da diferença existente entre a brincadeira e a realidade imediata que lhe forneceu conteúdo para realizar-se... No ato de brincar, os sinais, os gestos, os objetos e os espaços valem e significam outra coisa daquilo que aparentam ser. Ao brincar as crianças recriam e repensam os acontecimentos que lhes deram origem, sabendo que estão brincando."
}

O vestuário utilizado no Movimento Escoteiro tem o propósito de permitir a identificação, além de proporcionar conforto na realização das atividades, assim como evitar que a roupa signifique diferença entre os meninos e as meninas, além de "diferenciar o escoteiro do comum da sociedade" (Souza, 2010 p.33). Entre as peças mais relevantes do vestuário está o Lenço Escoteiro, um pedaço triangular de tecido com cores e inscrições que especificam o Grupo Escoteiro ao qual pertence e permite identificação dos escoteiros em todas as épocas e em toda parte do mundo. Ele é utilizado enrolado e preso com um anel de couro ao redor do pescoço, UEB (2019).

\section{METODOLOGIA}

O presente estudo é constituído por uma pesquisa de caráter qualitativo, tendo a busca pela literatura embasada em Richardson (2010), que alega que revisar o conhecimento acumulado proporciona compreender o que tem sido realizado com referência ao fenômeno em estudo. Severino (2010), argumenta que o referencial teórico tem como pressuposto contextualizar as diversas categorias explicativas necessárias para analisar os fenômenos que são objeto da pesquisa. Ferreira (2015) aponta que a revisão da literatura deve ser concebida apresentando os estudos mais substanciais a respeito do tema, abordando os autores e o ano de estudo, por meio de uma apresentação estruturada e lógica. 


\section{REVISTA ENIAC PESQUISA}

\section{PROGRESSÃO PESSOAL RAMO LOBINHO}

No Ramo Lobinho são oferecidas 50 competências que abrangem duas fases, a infância média, seis e meio a oito anos, e a infância tardia, nove a dez anos. UEB (2016), o Caminho de Jângal, é definido como o conjunto de cinco passos dados pelas crianças, dão início a partir do ingresso na Alcateia e terminam com sua passagem para a tropa escoteira. O Caminho de Jângal é dividido por cinco trechos e marcado por distintivos diferentes representados na Tabela 2.

Tabela 2. O Caminho de Jângal (UEB, 2016)

\begin{tabular}{c|c|c}
\hline Caminho & Nome do Distintivo \\
\hline Caminho do Integrar & Pata Tenra & Saltador \\
\hline Caminho do Descobrir & Rastreador \\
\hline Caminho do Rastrear & Caçador \\
\hline Caminho do Caçar & & \\
\hline
\end{tabular}

Fonte: Elaborado pelos autores

As competências são associadas a cada uma dessas fases e à idade de cada criança.

Sendo, a $1^{a}$. fase organizada para as crianças entre 6,5 e 9 anos e, crianças de 9 a 10 anos, 
referem-se à $2^{\mathrm{a}}$. fase. Correlacionado a cada uma das competências, são sugeridas atividades que ajudam o jovem no desenvolvimento daquele objetivo educacional. A Tabela 3 a seguir aborda exemplo de competência na área de desenvolvimento intelectual, proposta para o Ramo Lobinho.

Tabela 3 : Competência e atividades no Ramo Lobinho UEB (2016)

\begin{tabular}{|c|c|}
\hline Competências & Atividades propostas \\
\hline \multicolumn{2}{|r|}{ Fase 1} \\
\hline \multirow[t]{3}{*}{$\begin{array}{l}\text { Demonstra interesse por aprender e } \\
\text { por conhecer e manipular novos } \\
\text { objetos }\end{array}$} & $\begin{array}{c}\text { Conhecer o material individual para um } \\
\text { acampamento/acantonamento, arrumar a sua mochila e } \\
\text { embalar um saco de dormir, de modo que possa ser } \\
\text { transportado corretamente. }\end{array}$ \\
\hline & Aprender cinco frases úteis em outro idioma. \\
\hline & $\begin{array}{c}\text { Acertar a maioria dos objetos num jogo Kim (de visão, } \\
\text { audição, tato, olfato ou paladar). }\end{array}$ \\
\hline \multicolumn{2}{|r|}{ Fase 2} \\
\hline \multirow{3}{*}{$\begin{array}{l}\text { Desenvolve a capacidade para } \\
\text { pesquisar, interrogar e descobrir as } \\
\text { causas dos fenômenos que observa e } \\
\text { soluções para pequenos problemas. }\end{array}$} & $\begin{array}{c}\text { Conhecer a Rosa dos Ventos e o Cruzeiro do Sul, reconhecê- } \\
\text { lo no céu e saber se orientar por ele. }\end{array}$ \\
\hline & Fazer uma compra e prestar contas do pagamento. \\
\hline & $\begin{array}{l}\text { Fazer os nós de escota, escota alceado, volta do fiel, saber } \\
\text { para que servem e aplicá-los numa atividade. }\end{array}$ \\
\hline
\end{tabular}

Fonte: Elaborado pelos autores

Como componente integrante ao desenvolvimento de cada jovem, é apresentado um planejamento para conquista de especialidades, com distintivos correlatos a cinco ramos de conhecimento: ciência e tecnologia, serviços, cultura, desportos, habilidades escoteiras, detalhado na Tabela 4. Em cada uma das especialidades, são apresentadas diversas tarefas que o jovem precisará completar. De acordo com UEB (2016), para conquistar a especialidade em seu primeiro nível, o jovem precisará cumprir um terço das tarefas propostas. Quando cumprir dois terços, conquista o segundo nível e, cumprindo todos os itens, o terceiro nível, recebendo assim o distintivo referente à especialidade.

Tabela 4. Ramos de conhecimento e exemplos de especialidades UEB (2016) 


\begin{tabular}{c|c}
\hline Ramos de conhecimento & Exemplos de especialidades \\
\hline Ciência e tecnologia & Anatomia humana, comunicação, egiptologia, robótica \\
\hline Serviços & Administração, churrasco, segurança doméstica, trabalho voluntário \\
\hline Cultura & Anime, cultura brasileira, história da arte, mitologia \\
\hline Desportos & Artes marciais, cubo mágico, esgrima, xadrez \\
\hline Habilidades escoteiras & Acampamento, cidadania do mundo, ferramentas de corte, rastreamento \\
\hline
\end{tabular}

Fonte: Elaborado pelos autores

Dentre as especialidades distribuídas nos cinco ramos de conhecimento do Movimento Escoteiro, abrangendo temas desde artesanato à mitologia. os distintivos representam o conhecimento adquirido. A Figura 2 representa o distintivo de Comunicações que é um exemplo do ramo de conhecimento Ciência e Tecnologia com alguns itens de atividade elencados, segundo https://www.escoteiros.org.br/especialidades/, em 25.10.2020:

1. "Montar 1 (um) painel mostrando as diferenças entre os meios de comunicação dos dias atuais e aqueles do passado.

2. Transmitir uma mensagem utilizando Código Morse ou semafórico.

3. Elaborar 1 (um) editorial para 1 (um) jornal.

4. Elaborar uma propaganda para televisão e 1 (um) pequeno texto com efeitos sonoros para rádio."

Figura 2 - Distintivo de Comunicações

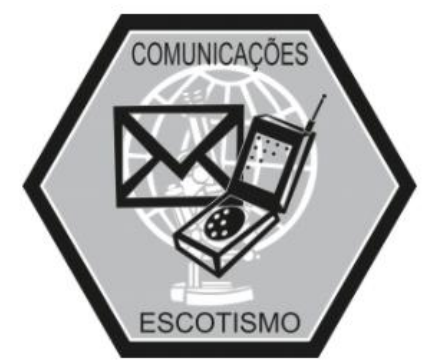

Fonte: Escoteiros do Brasil, 2021.

Desta maneira, o lobinho vai adquirindo distintivos conforme cumpre as atividades sugeridas de um determinado ramo de conhecimento adquirindo assim competências. 


\section{RESULTADOS E DISCUSSÕES}

Desde a mais tenra idade, constantemente em todos os lugares e situações diante de cenários, cenários estes que exigem tomada de decisões, decisões estas que fazem o indivíduo aprender e construir um saber que é sempre progressivo.

O escotismo é um movimento que procura construir conhecimento por meio da educação não formal tendo como premissa a integridade do sujeito, sua conexão com a natureza e a sociedade e a preocupação com a contribuição para a educação de seus participantes. Através do método escoteiro que se caracteriza pelo método educativo do movimento, seus integrantes vão construindo os saberes através da conquista de competências por meio das experiências vivenciadas, "ao invés de conformar-se a um protótipo concebido, ou até mesmo imposto por seus familiares mais velhos, encontra sua personalidade e identidade através de sua própria iniciativa" Nagy (1987, p.202). As competências, quando absorvida pelo lobinho e comprovada através das fases, é transformada em distintivo. A representação dos distintivos no uniforme dos escoteiros demonstra quais conhecimentos, habilidades, atitudes e saberes ele possui.

Traçando um paralelo entre as árvores de conhecimento e o movimento escoteiro na Tabela 5 compara-se cada elemento da estrutura da árvore com os elementos do movimento. Partindo do princípio de que os membros do movimento no Brasil são uma coleção de indivíduos formando um grupo com saberes e competências que compõem uma comunidade do saber.

Tabela 5. Comparação entre a Árvore de Conhecimentos e o Movimento Escoteiro

\begin{tabular}{|c|c|c|}
\hline Elementos & Árvores de Conhecimento & Escoteiros \\
\hline Indivíduos & $\begin{array}{l}\text { Indivíduos em seu coletivo, } \\
\text { institucional ou não que participa do } \\
\text { crescimento de uma mesma árvore }\end{array}$ & $\begin{array}{l}\text { Membros do Movimento } \\
\text { Escoteiro no Brasil }\end{array}$ \\
\hline Competências & $\begin{array}{l}\text { Saberes, conhecimentos, habilidades e } \\
\text { atitudes representados pelas patentes }\end{array}$ & $\begin{array}{l}\text { Especialidades, conhecimentos, } \\
\text { habilidades e atitudes } \\
\text { representadas pelos distintivos }\end{array}$ \\
\hline Brasão & $\begin{array}{c}\text { Conjunto de patentes representando o } \\
\text { individuo }\end{array}$ & $\begin{array}{l}\text { Conjunto de distintivos } \\
\text { compondo o individuo }\end{array}$ \\
\hline Árvore de conhecimento & Comunidade de saber & Comunidade de saber \\
\hline
\end{tabular}

Fonte: Elaborado pelos autores 
Uma vez que os distintivos já estão capturados no uniforme dos escoteiros, a proposta deste ensaio teórico é sugerir a utilização das árvores de conhecimento para o movimento escoteiro onde todos membros do movimento estarão cadastrados e representados com seus respectivos distintivos na árvore de conhecimento da comunidade tendo o mapeamento das competências, conhecimentos e habilidades de todos os participantes devidamente registrados, de lobinhos a adultos podendo dividir por cada um de seus ramos.

A partir das reflexões apresentadas neste trabalho, o conceito de árvores de conhecimento avalia o crescimento de uma comunidade, sendo aplicado ao Movimento Escoteiro no Brasil permitiria a visualização das competências de todos os componentes participantes do escotismo. Cada integrante consegue acompanhar seus distintivos tanto em seu uniforme como no programa de software que foi desenvolvido por Lévy e Authier (1995) para ter os dados cadastrados em um sistema, gerando uma perspectiva visual da árvore. Nesta visualização da árvore o movimento escoteiro tem a perspectiva dos saberes e das competências como um todo, por ramo e mais especificamente de cada membro e cada um de seus membros pode visualizar-se na árvore.

\section{CONSIDERAÇÕES FINAIS}

O objetivo deste ensaio foi compreender as sinergias entre a organização dos saberes e competências do movimento escoteiro e sua disposição segundo a estrutura de árvores de conhecimento de Lévy e Authier (1995) entendendo como uma estrutura correlata. Diante das análises feitas através desta pesquisa, uma das conclusões é: o Movimento Escoteiro dispõe de um programa educativo que propicia aos seus membros o desenvolvimento de competências relacionadas a diversas áreas de conhecimento, possibilitando a estes jovens membros adquirir e aperfeiçoar conhecimentos, habilidades e atitudes que se somam às competências já existentes gerando um constante progresso no aprendizado. Adicionalmente a pesquisa, retrata que a estrutura de saberes do movimento escoteiro pode ser simbolizado na estrutura de árvores de conhecimento.

Outro ponto observado através desta pesquisa é de que o Movimento Escoteiro, apesar de iniciado em 1900, é um tema pouco estudado com uma restrita literatura 
científica, apesar de contar com milhões de membros em todo o mundo, sugere-se contribuições para o desenvolvimento de estudos do movimento como um todo, tais como retratar o movimento escoteiro na perspectiva do terceiro setor, a análise do ponto de vista da administração do movimento, estudos de caso do progresso das competências individuais desenvolvidas durante a participação no movimento e o impacto para a vida e formação da personalidade, entre tantos outros. É um movimento muito rico de conhecimento e pode ser explorado em diversas áreas do conhecimento. A presente pesquisa abordou a sessão do Ramo Lobinho, o que representa uma limitação do estudo.

\section{REFERÊNCIAS}

Ausubel, D.P. (1968). Education psychology : A cognitive view.. New York, Holt, Rinehart and Winston Inc.

Baden-Powell, R. S. S. (1908) Scounting for boys : A handbook for instruction in good citizenship. London Horace Cox. Windsor House, Bream’s Buldings, E.C., 1908.

Baden-Powell, R. S. S. (1985). O Manual do Lobinho (The Wolf cubs handbook). Trad. União dos Escoteiros do Brasil. Rio Grande do Sul: União dos Escoteiros do Brasil, 19101924.

Brandão, H. P. (2009) Aprendizagem, contexto, competência e desempenho: um estudo multinível. 2009. 345 f. Tese (Doutorado)-Curso de Psicologia Social do Trabalho e das Organizações, Departamento de Instituto de Psicologia, Universidade de Brasília, Brasília, Brasil.

Brasil. Ministério da Educação e do Desporto. Secretaria de Educação Fundamental. (1998). Referencial curricular nacional para a educação infantil. Brasília: MEC/SEF.

Durand, T. (1998). “The Alchemy of Competence." In Strategic Flexibility: Managing in a Turbulent Environment, edited by G. Hamel, C. K. Prahalad, H. Thomas, and D. O'Neal, 303-330. New York: Wiley.

Escoteiros do Brasil. (2021). Comunicações. Recuperado de https://www.escoteiros.org.br/especialidades/comunicacoes/

Ferreira, M. P. (2015). Pesquisa em administração e ciências sociais aplicadas. Grupo Gen-LTC.

Fleury, M. T. L.; Fleury, A. (2001). Construindo o conceito de competência. Revista de Administração Contemporânea, 5(spe), pp. 183-196. 
Kipling, R., \& Haddad, J. A. (1954). O livro da Jângal. Companhia Editora Nacional.

Lévy, P. e Authier, M. (1995) : As árvores do conhecimento. Rio de Janeiro: Bertrand Brasil.

Mcclelland, D. C. (1973) Testing for competence rather than intelligence. American Psychologist, n. 28, p. 1-4.

Mirabile, R. J., (1997) Everything you wanted to know about competency modeling. : Training \& Development(Vol. 51, Issue 8).

Nagy, L. (1987). 250 milhões de escoteiros; Trad. Jairo Antunes da Costa Rio Grande do Sul: Editado pela União dos Escoteiros do Brasil.

Organização Mundial do Movimento Escoteiro. (2020). National Scout Organizations. Disponivel em: <https://www.scout.org/worldwide>. Acesso em: 01 de novembro de 2020.

Perrenoud, P.(1999) : Construir as competências desde a escola; trad. Bruno Charles Magne, Porto Alegre: Artes Médicas Sul.

Pestalozzi, J. (1898). How Gertrude teaches her children. Syracuse, NY: C. W. Barden.

Powell, B. (1986). Escotismo para rapazes. Edição da Fraternidade Mundial. Rio: União dos Escoteiros do Brasil-UEB.

Richardson, R. J., \& Peres, J. A. (2010). Pesquisa social: métodos e técnicas. São Paulo: Atlas. $3^{\text {a }}$. edição

Santos, A. C., \& Feldens, D.G. (2014). O "Scouting for Boys" abre para mulheres: a implantação da co-educação no escotismo brasileiro. Cadernos De História Da Educação, 12(2). Recuperado de http://www.seer.ufu.br/index.php/che/article/view/25012

Severino, A. J. (2010). Metodologia do trabalho científico. Cortez editora. $23^{\text {a }}$.edição

Souza, M.E.B. (2010). Pensamento social conservador na modernidade brasileira contemporânea: estudo de caso sobre o movimento escoteiro. Dissertação (Mestrado)Curso de Sociologia, Departamento de Sociologia da Faculdade de Filosofia, Letras e Ciências Humanas, Universidade de São Paulo, São Paulo, 2010

Smith, M. K. What is non-formal education? (1996). Disponível em https://infed.org/whatis-non-formal-education/\#idea.

Thomé, N. (2006). Movimento escoteiro: projeto educativo extra-escolar. Revista HISTEDBR On-line, 23, 171.

UNESCO (2011) International Standard Classification of Education - ISCED. Montreal; Quebec: Unesco: Institute for Statistics. 
União dos Escoteiros do Brasil. (1998). Manual do escotista : ramo lobinho : um método de educação não formal para meninos e meninas de 7 a 11 anos. Curitiba: Autor. ISBN 8587050-01-X

União dos Escoteiros do Brasil. (2011). Estatuto da União dos Escoteiros do Brasil. Recuperado de https://www.escoteiros.org.br/arquivos/documentos_oficiais/estatuto_UEB_2011.pdf

União dos Escoteiros do Brasil. (2016). Escotistas em ação! - Ramo Lobinho. (2 ed.). Curitiba: Autor.

Recuperado de https://escoteiros.org.br/arquivos/programa/Escotistas_em_acao_ramo_lobinho.pdf

União dos Escoteiros do Brasil. (2018). Política Nacional do programa Educativo: vivendo aventuras, transformando pessoas. Curitiba: Autor. Recuperado de https://www.escoteiros.org.br/wpcontent/uploads/2020/07/Poli\%CC $\% 81$ tica_nacional_de _programa_educativo.pdf

União dos Escoteiros do Brasil (2019). POR - Princípios Organização e Regras. (10 ed.). Curitiba: Autor. Recuperado de https://www.escoteiros.org.br/wpcontent/uploads/2016/01/por.pdf 